ARTICLE

DOI: 10.1038/s41467-017-00973-y

\title{
Fast-charging high-energy lithium-ion batteries via implantation of amorphous silicon nanolayer in edge-plane activated graphite anodes
}

\author{
Namhyung Kim (1) ${ }^{1}$, Sujong Chae ${ }^{1}$, Jiyoung $\mathrm{Ma}^{1}$, Minseong $\mathrm{Ko}^{1,2} \&$ Jaephil Cho ${ }^{1}$
}

As fast-charging lithium-ion batteries turn into increasingly important components in forthcoming applications, various strategies have been devoted to the development of high-rate anodes. However, despite vigorous efforts, the low initial Coulombic efficiency and poor volumetric energy density with insufficient electrode conditions remain critical challenges that have to be addressed. Herein, we demonstrate a hybrid anode via incorporation of a uniformly implanted amorphous silicon nanolayer and edge-site-activated graphite. This architecture succeeds in improving lithium ion transport and minimizing initial capacity losses even with increase in energy density. As a result, the hybrid anode exhibits an exceptional initial Coulombic efficiency (93.8\%) and predominant fast-charging behavior with industrial electrode conditions. As a result, a full-cell demonstrates a higher energy density ( $\geq 1060 \mathrm{WhI}^{-1}$ ) without any trace of lithium plating at a harsh charging current density $\left(10.2 \mathrm{~mA} \mathrm{~cm}^{-2}\right)$ and 1.5 times faster charging than that of conventional graphite.

\footnotetext{
${ }^{1}$ School of Energy and Chemical Engineering Green Energy Materials Development Center, Ulsan National Institute of Science and Technology (UNIST), Ulsan 44919, Republic of Korea. ${ }^{2}$ Department of Metallurgical Engineering, Pukyong National University, Busan 48547, Republic of Korea. Correspondence and requests for materials should be addressed to M.K. (email: msko876@pknu.ac.kr) or to J.C. (email: jpcho@unist.ac.kr)
} 
W ith rapidly increasing demands to reduce the charging time of portable electronics and electric vehicles, achieving fast charging in lithium-ion batteries (LIBs) with high-energy density has been intensively pursued as the most important criterion for practical utilization in forthcoming applications. However, conventional graphite anodes have been limited in terms of fast charging by the metallic lithium plating phenomenon caused by its sluggish intercalation kinetics ${ }^{1-3}$ and low lithiation voltage $\left(0.08 \mathrm{~V} \text { vs. } \mathrm{Li} / \mathrm{Li}^{+}\right)^{4}$. In particular, at a high charging current, large anode polarization pushes the graphite potential to the threshold for metallic $\mathrm{Li}$ deposition ${ }^{5}$. The deposited $\mathrm{Li}$ also undergoes electrical isolation ${ }^{6}$ and reaction with the electrolyte ${ }^{7,8}$, which increase the internal resistance and decrease the energy density ${ }^{9}, 10$. In general, it is known that conventional graphite electrodes suffer from Li deposition giving rise to rapid capacity fading, even at a charging current density of $4 \mathrm{~mA} \mathrm{~cm}^{-211,12}$

Alternatively, silicon has been highlighted as a feasible candidate with a gravimetric capacity $\left(3572 \mathrm{mAh} \mathrm{g}^{-1}\right)$ that is 10 times that of graphite and a safer lithium-alloying potential $(0.22 \mathrm{~V}$ vs. $\left.\mathrm{Li} / \mathrm{Li}^{+}\right)$, which prevents undesirable Li plating ${ }^{4}{ }^{13}$. Nevertheless, its fast charge performance deteriorates owing to the extreme volume change $(>300 \%)$ and poor electrical conductivity $\left(\sim 10^{-4}\right.$ $\mathrm{S} \mathrm{m}^{-1}$ ), resulting in disintegration of the electrode and a high charge-transfer resistance ${ }^{13-17}$.

For these reasons, various strategies have been explored to enhance the rate property of both the anodes via the designing of porous structures (e.g., $\mathrm{KOH}$ etched graphite ${ }^{12}, \mathrm{MoO}_{x^{-}}$ catalyzed porous graphite $e^{18}$, or 3D mesoporous silicon ${ }^{19}, 20$ ) and composites with a conductive matrix (e.g., graphite with vaporgrown carbon fibers ${ }^{21}$, carbon-nanotube-graphene anchored silicon $^{22,}$ 23, or silicon-metal composites ${ }^{24}{ }^{25}$ ). However, even though such approaches can enhance the reactivity with $\mathrm{Li}^{+}$ions and electron transport through largely exposed surface areas and conducting material, their application in high-energy LIBs are still hindered by the poor initial CE, low tapping density, and excessive proportion of the conducting matrix.

In order to realize high-energy density in electrodes, the fabrication process should be designed by taking into consideration the industrial conditions involving high areal capacity loading $\left(\geq 3.0 \mathrm{mAh} \mathrm{cm}^{-2}\right)$ and high electrode density $\left(\sim 1.6 \mathrm{~g} \mathrm{~cm}^{-3}\right)$ under the limited amount of binder $(\leq 3 \mathrm{wt} \%)$ and conductive materials $(\leq 1 \mathrm{wt} \%)$. Since such electrode parameters are regarded as major limiting factors of the capability for fast charging ${ }^{26}$, electrochemical evaluation under these conditions is necessary to evaluate the feasibility of achieving fast-charging characteristics while maintaining high-energy density. However, most previously reported anodes designed for fast (dis)charging were simply studied under mild electrode conditions to demonstrate plausible electrochemical performance by using low areal mass loading, uncalendered electrodes, and excessive amounts of binders and conductive agents, which, in turn, bring about low-energy density. Therefore, it is important to design and fabricate fast-charging anodes with high-energy density.

To address these problems, we propose a novel Si-Graphite composite design, which not only possesses the enhanced kinetics for $\mathrm{Li}^{+}$but also satisfies the aforementioned industrial electrode conditions. We prepare a composite consisting of an edge-planeactivated graphite and a-Si nanolayer (SEAG) through nickelcatalyzed hydrogenation $\left(\mathrm{Ni}+\mathrm{C}_{\text {graphite }}+2 \mathrm{H}_{2} \rightarrow \mathrm{Ni}+\mathrm{CH}_{4}\right)^{27}, 28$ and chemical vapor deposition (CVD) using both acetylene $\left(\mathrm{C}_{2} \mathrm{H}_{2}\right)$ and silane $\left(\mathrm{SiH}_{4}\right)$ gas. In contrast to earlier approaches, the material design in the current work provided multiple attractive advantages. First, the catalytic reaction primarily activates the $\mathrm{Li}^{+}$-reactive edge plane of graphite ${ }^{28-31}$. According to previous studies, the mass-transfer kinetics of graphite can be improved by creating exposed edge sites ${ }^{32-34}$. As a result, the kinetics is enhanced with the minimized surface area, leading to a high initial CE. Second, the remaining Ni nanoparticles, which act as a catalyst for the activation reaction, improve the electric conductivity of SEAG ${ }^{35}$. Third, despite the catalytic hydrogenation, the graphite core still remains as a supporting framework that withstands high mechanical pressure during electrode calendering ${ }^{36}$. Besides, since the dense core may have sustained the tap density of the composite ${ }^{24,37}$, such features are more favorable to the attainment of high electrode density. Fourth, the nanoscale Si coating layer increases the energy density of the material and allows fast Li diffusion owing to its high specific capacity, and shortened the $\mathrm{Li}^{+}$diffusion length ${ }^{38,39}$. Finally, all the synthesis methods consist of simple processes. In particular, the heat treatment, including the catalytic hydrogenation, and CVD procedures can be conducted as a continuous process in the same furnace. Together, these advantages strengthen the commercial feasibility of SEAG in fast-charging high-energy LIBs.

\section{Results}

Materials synthesis and structural design. The schematic in Fig. 1a illustrates the procedures for the fabrication of SEAG composite. Mesocarbon microbeads (MCMBs), which are widely adopted as a commercial anode with high tap density $\left(1.38 \mathrm{~g} \mathrm{~cm}^{-3}\right)$ and excellent CE in the 1st cycle (95.7\%), were used as pristine graphite. At first, spherical nickel nanoparticles with a size of $\sim 500 \mathrm{~nm}$ were formed on the pristine graphite via a simple reflux method at $80^{\circ} \mathrm{C}$. The sample was then calcined at $1000^{\circ} \mathrm{C}$ in a hydrogen $\left(\mathrm{H}_{2}\right)$ atmosphere to trigger the catalytic hydrogenation reaction between nickel and graphite. As carbon atoms were hydrogenated, the adsorbed $\mathrm{Ni}$ nanoparticles penetrated the graphite core with methane $\left(\mathrm{CH}_{4}\right)$ gas evolution, resulting in a holey structure. Note that it was thermodynamically more favorable for the catalytic gasification of carbon to take place on the edge plane than on the basal plane of graphite ${ }^{27-31}$. As a final step, a graphitic carbon shell and an amorphous $\mathrm{Si}(\mathrm{a}-\mathrm{Si})$ nanolayer were homogeneously distributed on nickel and graphite, respectively, via consecutive CVD processes using $\mathrm{C}_{2} \mathrm{H}_{2}$ and $\mathrm{SiH}_{4}$ gases (details are given in the "Methods" section). Additionally, the elemental composition of SEAG was analyzed by various kinds of methods, including inductively coupled plasma optical emission spectrometry, thermogravimetric analysis, and elemental analyzer (Supplementary Fig. 1 and Supplementary Table 1).

For the detailed elucidation of its unique structural characteristics, the cross-section of SEAG is schematically shown in Fig. 1b. The Ni nanoparticle pierces the graphite along the edge plane, while it functions as a catalyst for the gasification of carbon. A high-resolution transmission electron microscope (HR-TEM) image of the embedded $\mathrm{Ni}$ is shown in Fig. 1c. Owing to the catalytic reaction, unrevealed edge planes emerged, and these activated edges improved the mass-transfer property of $\mathrm{Li}^{+}$ions with enlarged electrochemically active sites. To demonstrate the enhanced kinetics for $\mathrm{Li}^{+}$, we conducted cyclic voltammetry and estimated the relative electrochemically active surface area of the edge-activated graphite (EAG) from the relationship between the peak current and scan rate, described by the Randles-Sevcik equation (Fig. 1d and Supplementary Fig. 2) ${ }^{40}$. According to this equation, the slope of the plot in Fig. 1d is proportional to the active surface area (details are described in Supplementary Note 1). As a result, the $\mathrm{Li}^{+}$-reactive surface area in EAG was about twice that of pristine graphite. Furthermore, despite the activation process, SEAG still had the inner core as a ductile framework, which enabled it to be easily calendered to yield a high electrode density. 
a
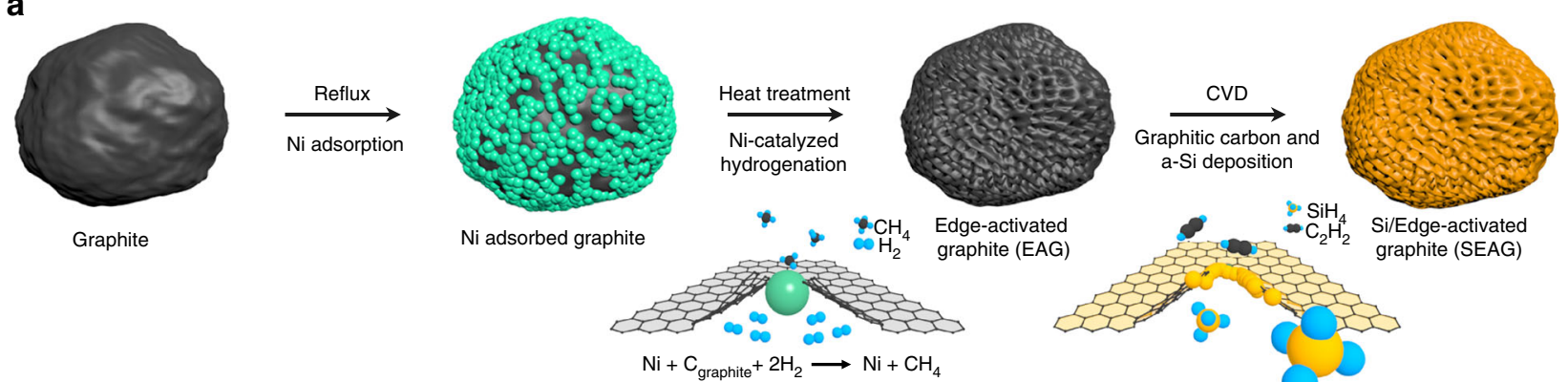

b

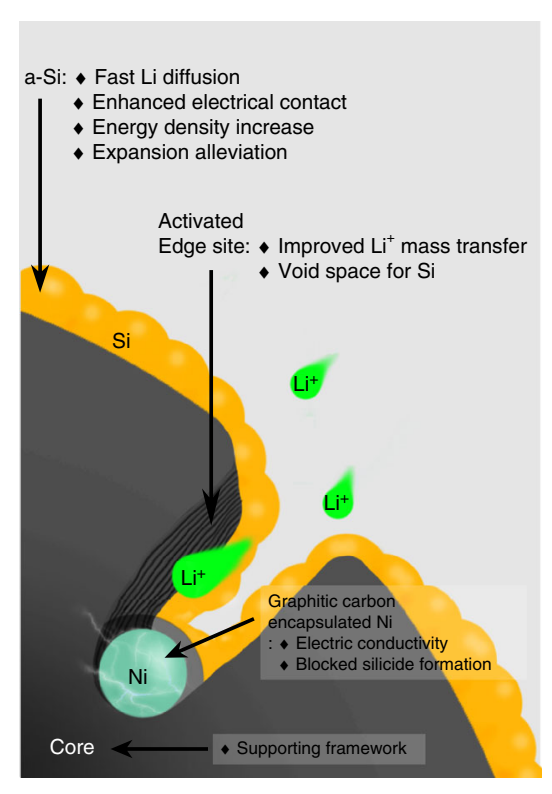

C

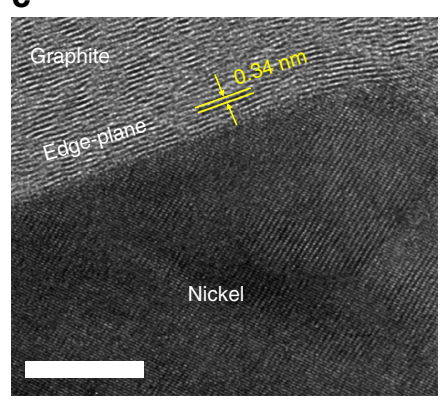

d

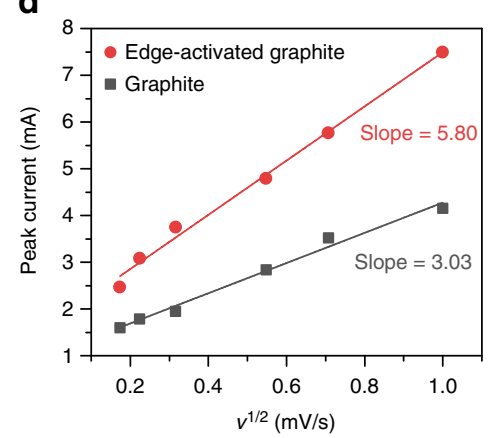

g
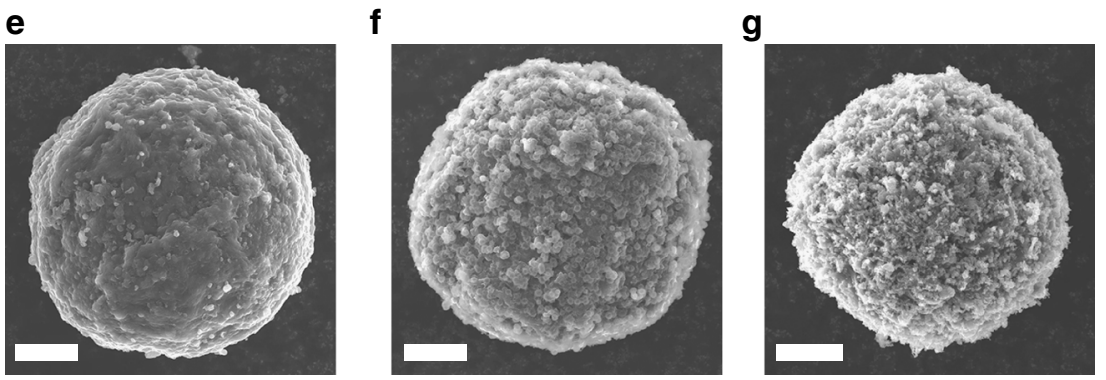

Fig. 1 Schematic of the procedures for fabrication and characterization of SEAG. a Fabrication of SEAG: the adsorbed Ni penetrated graphite via catalytic hydrogenation at $1000^{\circ} \mathrm{C}$, which led to edge-plane activation on the surface of graphite. $\mathbf{b}$ Cross-sectional illustration showing the detailed structural characteristics of SEAG. c HR-TEM image of a Ni nanoparticle embedded in EAG. d Relationship between the square root of the scan rate and the peak current: the slope indicates the relative electrochemically active surface area. SEM images of pristine graphite $\mathbf{e}$, graphite with adsorbed Ni on its surface $\mathbf{f}$, and the SEAG composite $\mathbf{g}$. Scale bars, $5 \mathrm{~nm} \mathbf{c}, 5 \mu \mathrm{m} \mathbf{e}, \mathbf{f}, \mathbf{g}$

The alloying reaction of the remaining Ni nanoparticles in EAG into Ni silicide inevitably occurred under the $\mathrm{SiH}_{4}$ atmosphere, before the gas decomposition temperature was reached, because of the high reactivity with Si (Supplementary Fig. 3$)^{41-43}$. Unfortunately, this alloying reaction had critical influences on the electrochemical performance, such as decreasing the gravimetric capacity by Si consumption, reducing the electrical conductivity of $\mathrm{Ni}^{44}$, and causing an irreversible capacity with a poor initial $\mathrm{CE}^{45}$. Thus, a well-defined barrier against silicide formation was necessary to secure good battery performance. Hence, the CVD processes using $\mathrm{C}_{2} \mathrm{H}_{2}$ and $\mathrm{SiH}_{4}$ were successively employed to develop the protective carbon shell on $\mathrm{Ni}$, followed by a Si coating layer. Because of the high carbon solubility of nickel ${ }^{46}$, the electrically conductive graphitic shell was deposited mainly on the nickel nanoparticles, and then the Si layers were uniformly formed on both the surface of this shell and graphite without the formation of $\mathrm{Ni}$ silicide. The homogeneous a-Si nanolayer led to fast $\mathrm{Li}^{+}$diffusion and alleviated volume expansion while attaining high-energy density. These Si layers synthesized by the CVD method could establish good electrical contact with graphite by adhering well onto the graphite surface ${ }^{38}$. Scanning electron microscope (SEM) images of pristine graphite, graphite with adsorbed $\mathrm{Ni}$, and SEAG are shown in Fig. 1e-g, respectively.
Physical characterization. We carried out X-ray diffraction (XRD) measurements, the analysis for the particle size distribution and tap density, and Brunauer-Emmett-Teller (BET) measurements to evaluate the physical properties of SEAG (Fig. 2). The characteristic peaks in the XRD pattern (Fig. 2a) indicate the existence of graphite; however, $\mathrm{Si}$ peaks are absent because the $\mathrm{Si}$ layer on the SEAG was amorphous ${ }^{47}$. The average diameter of the SEAG particles was $22 \mu \mathrm{m}$, which is almost the same as that of pristine graphite (Fig. 2b). Moreover, the tap density was measured as $1.27 \mathrm{~g} \mathrm{~cm}^{-3}$ in SEAG, which is comparable to that of pristine graphite but higher than that of conventional natural graphite (NG) (Fig. 2c). The BET-specific surface area of SEAG was estimated to be $2.49 \mathrm{~m}^{2} \mathrm{~g}^{-1}$ (Fig. 2d), which is slightly higher than that of pristine graphite, but still in the range obtained for conventional NG. Since irregular particle-size distribution, low tap density, and excessively large surface area are unfavorable for electrode preparation owing to inhomogeneous slurry mixing ${ }^{48}$, SEAG is expected to be advantageous for conventional electrode fabrication.

Structural characterization of SEAG composite. We performed SEM analysis with a focused ion beam (FIB) and HR-TEM analysis with a high-angle annular dark field scanning 
a

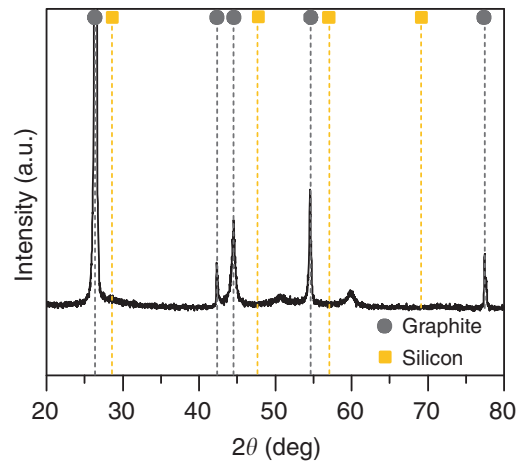

C

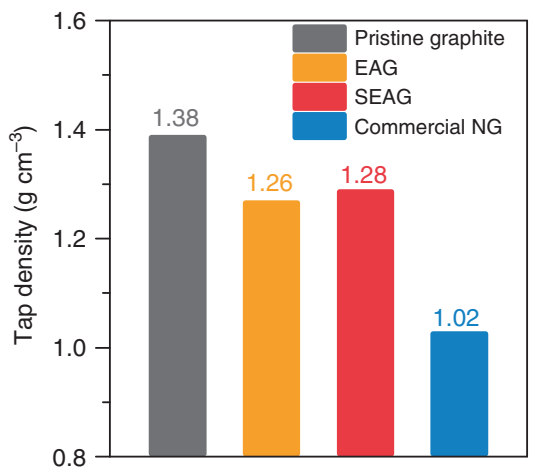

b



d

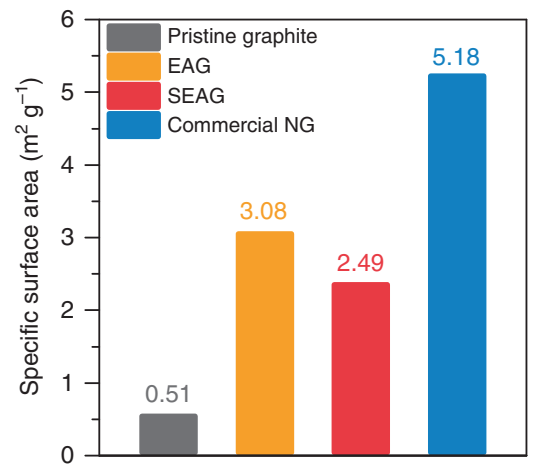

Fig. 2 Physical properties of SEAG. a XRD pattern of SEAG. b Statistical analysis of the particle-size distribution of pristine graphite (gray) and SEAG (red). c Tap density and $\mathbf{d}$ specific surface area of pristine graphite (gray), EAG (orange), SEAG (red), and conventional NG (blue)

a

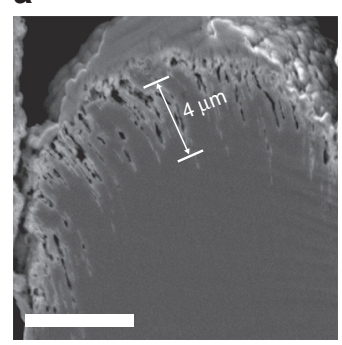

d

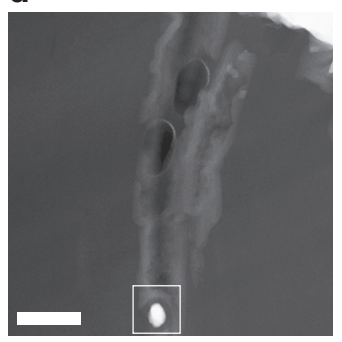

b

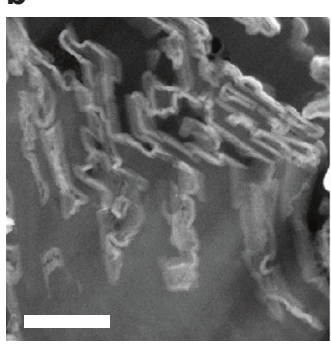

e
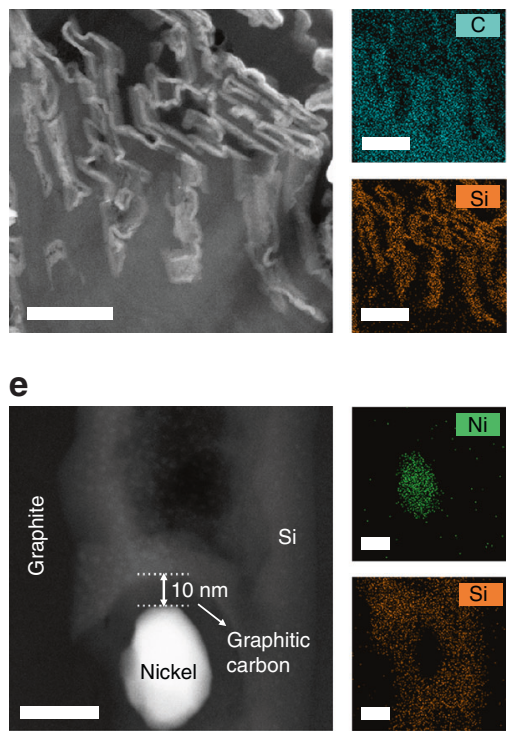

C

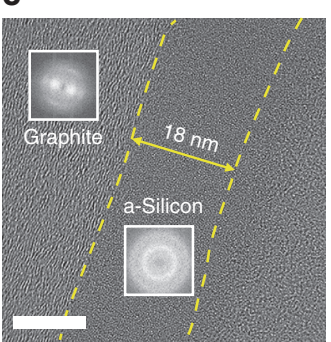

f

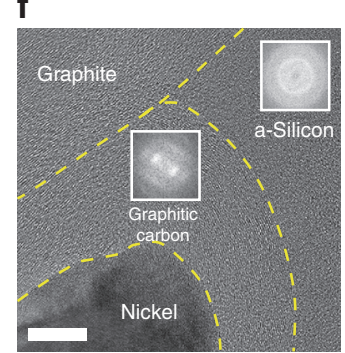

Fig. 3 Detailed investigation of cross-sectional SEAG. a SEM image of SEAG in cross-sectional view: SEAG maintained a rigid inner graphite framework despite going through catalytic hydrogenation. HAADF-STEM images with EDS mapping analysis of $\mathbf{b}$ the activated holes and silicon nanolayer on the graphite surface and $\mathbf{d}$ the nickel nanoparticle piercing the core of graphite. e Magnified HAADF-STEM image of $\mathbf{d}$. HR-TEM images at the interfacial region of $\mathbf{c}$ SEAG and $\mathbf{f}$ a nickel nanoparticle; fast Fourier-transform images are shown in the insets. The nickel nanoparticle was clearly separated from silicon by the graphitic carbon shell, which prevented the unfavorable formation of Ni silicide. Scale bars, a $5 \mu \mathrm{m}, \mathbf{b} 1 \mu \mathrm{m}, \mathbf{c}, \mathbf{f} 10 \mathrm{~nm}$, d $200 \mathrm{~nm}$, e $30 \mathrm{~nm}$

transmission electron microscope (HAADF-STEM) for detailed characterization of SEAG (Fig. 3). As shown in the cross-sectional SEM image (Fig. 3a), SEAG retained the sturdy inner graphite framework that withstands mechanical pressure even though it underwent catalytic hydrogenation, which is advantageous for increasing the electrode density. The HAADF-STEM image shows the magnified cross-sectional morphology of the SEAG (Fig. 3b). Contrary to the dense interior of pristine graphite (Supplementary Fig. 4), the micrometer-sized holes (average depth of $4 \mu \mathrm{m}$ ) in SEAG were well arranged on the surface in one 
a

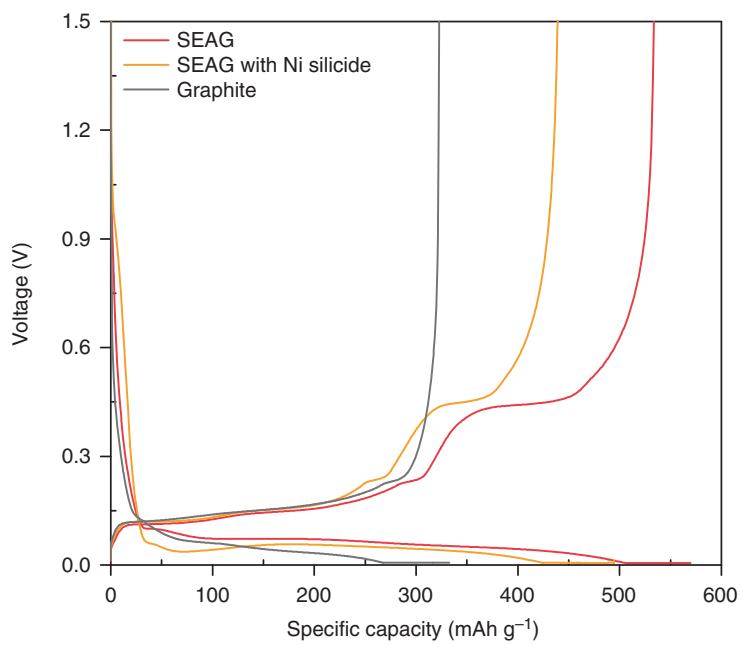

C

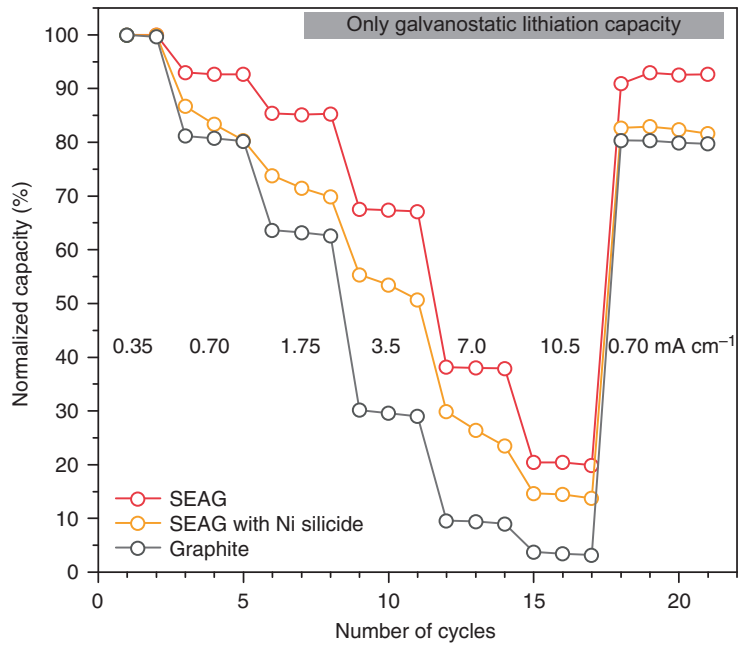

b

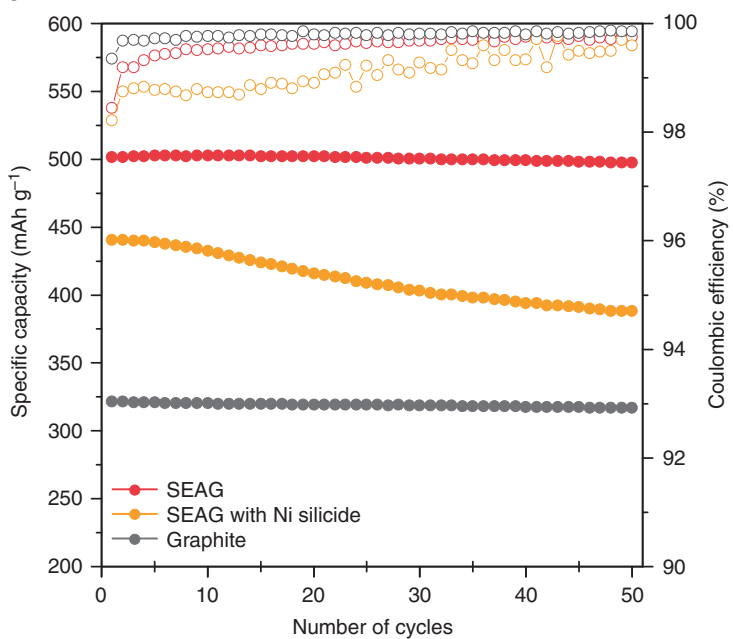

d

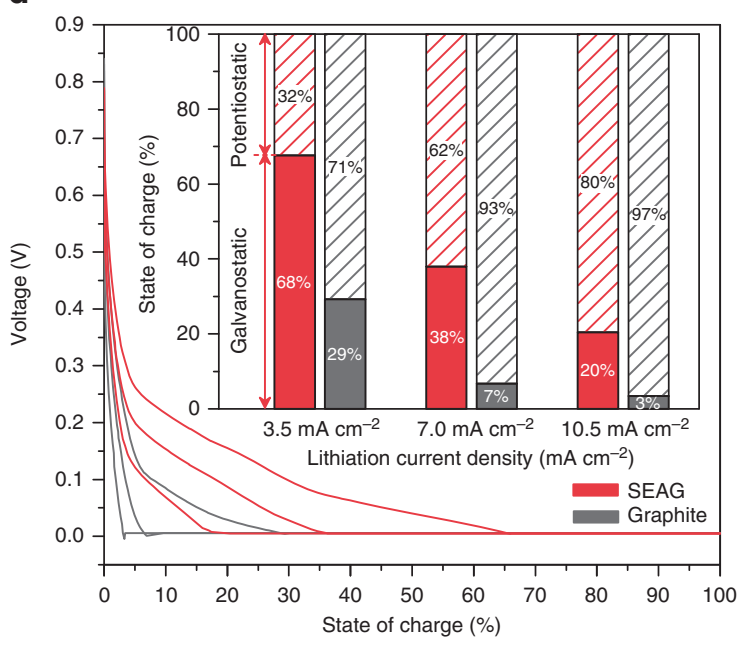

Fig. 4 Electrochemical characterization of various anodes in half-cell configurations. a Voltage profiles of SEAG, SEAG with Ni silicide, and graphite in the 1st cycle. $\mathbf{b}$ Plots of reversible capacity and cycling CE vs. cycle number for SEAG, SEAG with Ni silicide, and graphite over 50 cycles. The a 1 st cycle and $\mathbf{b}$ cycling test were carried out at current densities of 0.35 and $1.75 \mathrm{~mA} \mathrm{~cm}^{-2}$, respectively $\left(1 \mathrm{C}=3.5 \mathrm{~mA} \mathrm{~cm}^{-2}\right)$. c Galvanostatic charge capacities of SEAG under various lithiation current densities from 0.35 to $10.5 \mathrm{~mA} \mathrm{~cm}^{-2}$, compared to SEAG with Ni silicide and graphite. d Voltage profiles during charging process of SEAG and graphite, measured at increasing current densities from 3.5 to $10.5 \mathrm{~mA} \mathrm{~cm}$; the inset shows a plot of SOC divided into galvanostatic/potentiostatic stages at each current density

side of the particle, and the Si layer coated the inner holes as well as the outer surface of graphite. It was clarified via energy-dispersed X-ray spectroscopy (EDS) mappings of elemental carbon (cyan) and Si (orange) in SEAG (Fig. 3b). In addition, the HRTEM image with fast Fourier transform analysis shows that the aSi layer with thickness of $\sim 18 \mathrm{~nm}$ coated the graphite surface (Fig. 3c). Such incorporation of nanoscale a-Si in graphite could alleviate the stress and strain induced by the volume expansion and allow fast $\mathrm{Li}^{+}$diffusion ${ }^{38,49,50}$. X-ray photoelectron spectra (XPS) indicates the presence of a thin oxide layer on the a-Si surface due to the air exposure (Supplementary Fig. 5).

As shown in Fig. $3 \mathrm{~d}$ and e, a Ni nanoparticle that pierced the graphite core is completely enclosed within the graphitic carbon shell, leaving no space between $\mathrm{Ni}$ and carbon. Even though this graphitic carbon shell was only $10-\mathrm{nm}$ thick, it completely covered the entire Ni nanoparticle and blocked the penetration of $\mathrm{SiH}_{4}$ during the decomposition process. As shown by the EDS mapping analysis (Fig. 3e), elemental $\mathrm{Ni}$ (green) and $\mathrm{Si}$ (orange) are apparently separated from each other in the SEAG particle.
The HR-TEM image (Fig. 3f) and XRD analysis (Supplementary Fig. 6) clearly confirm the segregated existence of $\mathrm{Ni}$, graphitic carbon, and a-Si. Unlike amorphous carbon, the graphitic carbon provided high electrical conductivity ${ }^{51}$ and minimized the irreversible capacity loss caused by $\mathrm{Li}^{+}$trapping ${ }^{52}$. In short, the graphitic carbon shell could help address the crucial problems resulting from the formation of $\mathrm{Ni}$ silicide by efficiently blocking the penetration of $\mathrm{SiH}_{4}$. In addition, it enhanced the electrochemical properties of SEAG with its high electrical conductivity and low trapping of $\mathrm{Li}^{+}$.

Electrochemical performance of SEAG composite in half-cell. The electrochemical properties of SEAG were evaluated with a coin-type half-cell at $25^{\circ} \mathrm{C}$ to investigate the favorable effects of SEAG design on battery performance, especially the capability for fast charging (Fig. 4). All electrodes were fabricated with high areal capacity $\left(3.5 \mathrm{mAh} \mathrm{cm}{ }^{-2}\right)$, high electrode density $\left(1.6 \mathrm{~g} \mathrm{~cm}^{-3}\right.$, $\sim 33 \%$ of electrode porosity), and minimum use of binder 
materials ( $1.5 \mathrm{wt} \%$ of carboxymethyl cellulose and styrene butadiene rubber (SBR)) and conductive agent (1.0 wt \% of carbon black). Even under these challenging electrode conditions, the SEAG achieved an outstanding CE (93.8\%) with high specific capacity $\left(525 \mathrm{mAh} \mathrm{g}^{-1}\right)$ in the 1 st cycle (Fig. $\left.4 \mathrm{a}\right)$. To the extent of our knowledge, this is one of the highest values for initial CE among the previously reported graphite-Si composites. According to the differential capacity plot in Supplementary Fig. 7, it is clear that its higher specific capacity is owing to the contribution of Si nanolayer, and the total capacity of SEAG coincides well with the calculated value based on ICP-OES result (Supplementary Note 2). In addition, SEAG exhibited superior cycling stability for 50 cycles (Fig. 4b) with $99.3 \%$ capacity retention at a current density of $1.75 \mathrm{~mA} \mathrm{~cm}^{-2}$ (extended cycle performance and magnified plot of cycling efficiency are presented in Supplementary Figs. 8, 9). The outstanding electrochemical performances of SEAG are attributed to the uniform a-Si nanolayers and the enhanced electrical conductivity derived from the graphitic carbon capped with $\mathrm{Ni}$ nanoparticles. The post-cycling TEM analysis was conducted to verify the structural stability of SEAG during cycles (Supplementary Fig. 10). Furthermore, the effect of electrolyte additives on the cycle performance of SEAG was investigated and the result is shown in Supplementary Fig. 11. SEAG with $\mathrm{Ni}$ silicide exhibited an inferior electrochemical performance that included lower specific capacity (435 $\left.\mathrm{mAh} \mathrm{g}^{-1}\right)$, poor CE in the 1 st cycle $(88.5 \%)$, and severe capacity fading for 50 cycles ( $88 \%$ of initial capacity), indicating that blocking the formation of $\mathrm{Ni}$ silicide is of great importance for better performance.

To examine the lithiation behavior, which is highly affected by the over-potential, the rate capability of each sample was measured by only the galvanostatic method with lithiation current densities of $0.7-10.5 \mathrm{~mA} \mathrm{~cm}^{-2}$ (Fig. 4c). At higher applied currents, the lithiation capacity of graphite severely deteriorated, and exhibited only about $2 \%$ of the initial capacity $\left(8 \mathrm{mAh} \mathrm{g}^{-1}\right)$ at a high current density of $10.5 \mathrm{~mA} \mathrm{~cm}^{-2}$. On the other hand, EAG demonstrated improved lithiation behavior with high lithiation capacity at a current density of $7 \mathrm{~mA} \mathrm{~cm}^{-2}$, which was over twice that of graphite (Supplementary Fig. 12). In addition, such EAG electrode exhibited better fast-charging performance than that of graphite electrode containing $5 \mathrm{wt} \%$ of carbon black (Supplementary Fig. 13). These improvements suggest that the activation of unrevealed edge plane and embedded $\mathrm{Ni}$ nanoparticles could enhance both the mass and charge transfer kinetics during lithium intercalation. To the best of our knowledge, considering the electrode conditions, the lithiation rate capability of EAG in this study is the best performance reported among the graphite anodes (Supplementary Table 2).

Moreover, the rate property of SEAG was further improved with the incorporation of a-Si nanolayer. A specific lithiation capacity was obtained at $10.5 \mathrm{~mA} \mathrm{~cm}^{-2}$, which is almost $20 \%$ of the initial capacity $\left(100 \mathrm{mAh} \mathrm{g}^{-1}\right)$ and is 10 times the value obtained for graphite. This remarkable improvement supports our hypothesis that a homogeneous a-Si nanolayer allows high reactivity and fast diffusion for Li-ion transport ${ }^{49,50}$. Additionally, the differential capacity plot clearly shows that the enhanced performance of SEAG is owing to the unrevealed edge plane and a-Si nanolayer (Supplementary Fig. 14).

The fully lithiation properties, which were determined via both galvanostatic and potentiostatic methods, were further investigated in detail (Fig. 4d). The results are consistent with the previous rate properties estimated using only the galvanostatic stage: while SEAG showed a relatively mitigated voltage drop at each current density, graphite rapidly reached the cut-off voltage with severe over-potential, which is considered the main reason for both the long potentiostatic stage and Li-plating phenomenon.
As seen in the inset of Fig. 4d, most of the lithiation capacity (93 and $97 \%$ at 7.0 and $10.5 \mathrm{mAh} \mathrm{cm}^{-2}$, respectively) of graphite originated at the potentiostatic stage and almost 119 min were needed for fully lithiation at $10.5 \mathrm{mAh} \mathrm{cm}^{-2}$ (Supplementary Fig. 15). In contrast, a relatively large portion of lithiation capacity of SEAG was derived from the galvanostatic region with shorter charging time $\left(66 \mathrm{~min}\right.$ at $\left.10.5 \mathrm{~mA} \mathrm{~cm}^{-2}\right)$ because of its alleviated over-potential. It should be noted that it was difficult to control the charging time in the potentiostatic method because the current density became variable, and thus attaining fully lithiation on time was impeded by the prolonged potentiostatic process, even under high charging current density.

Fast-charging performance and volumetric energy in full-cell. To demonstrate the viability of using SEAG in practical applications, we performed a pouch-type full-cell evaluation with highvoltage $\mathrm{LiCoO}_{2}$ (LCO) as a cathode in the voltage range of 2.7-4.35 V (Fig. 5). The electrochemical performance of LCO in the half-cell is presented in Supplementary Fig. 16. The capacity ratio of negative to positive electrode (N/P ratio) was fixed at $1: 1$, with an areal cathode capacity of $3.4 \mathrm{mAh} \mathrm{cm}^{-2}$. At the formation cycle (at $0.34 \mathrm{~mA} \mathrm{~cm}^{-2}$ ), SEAG exhibited a high discharge capacity of $3.25 \mathrm{mAh} \mathrm{cm}^{-2}$ with a high CE of $92 \%$, which are comparable with the values obtained for graphite $\left(3.33 \mathrm{mAh} \mathrm{cm}^{-2}\right.$ with 94\% CE) (Supplementary Fig. 17). Also, SEAG demonstrated a competitive cycle stability at the current density of $1.7 \mathrm{~mA} \mathrm{~cm}$ compared to that of pristine graphite (Supplementary Fig. 18). Moreover, the cycling tests were conducted with various charging current densities $\left(5.1,7.7\right.$, and $\left.10.2 \mathrm{~mA} \mathrm{~cm}^{-2}\right)$ to investigate the fast-charging capability of each sample. The 1st voltage profiles at each current (Fig. 5a-c) clearly show that the SEAG occupies a lower over-potential with a shorter potentiostatic region than that of graphite. This result agrees well with the half-cell data presented in Fig. 4.

The cycling tests showed that the SEAG demonstrated better capacity retention over 50 cycles at all the current densities, whereas graphite exhibited drastic capacity fading after just 10 cycles (Fig. 5d-f). In the Coulombic efficiency plot, SEAG rapidly achieved a stabilized efficiency of $>97 \%$ at the 1 st CE, regardless of the applied charging current. On the other hand, graphite suffered from extremely unstable efficiency with increasing current density, especially during 10 cycles, with a low 1 st cycle efficiency of 92,86 , and $83 \%$ at each current density. These severe energy losses with the inferior CE are believed to be the result of irreversible Li metal plating on the electrode surface ${ }^{5-11}$. The overall voltage profiles of the cycling tests are presented in Supplementary Fig. 19.

In addition, we plotted the time required to charge to $80 \%$ of the state of charge (SOC) as applied charge current density (Fig. 5g). The SEAG electrode reached the SOC faster than graphite at all charging rates; the charging time of SEAG was much shorter (by a factor of $\sim 1.5$ ) because of its lower overpotential. Furthermore, the energy density is plotted as a function of charging current density in Fig. 5h (details of the measurements are given in Supplementary Table 3). As the applied current density was increased, a significant energy loss was observed at the graphite electrode $\left(726 \mathrm{Wh} \mathrm{l}^{-1}\right.$ at $\left.10.2 \mathrm{~mA} \mathrm{~cm}^{-2}\right)$. However, the SEAG electrode retained the highest volumetric energy even under a high charging current density $\left(1060 \mathrm{Wh} \mathrm{l}^{-1}\right.$ at $10.2 \mathrm{~mA} \mathrm{~cm}^{-2}$ ).

\section{Discussion}

To interpret the result of the fast-charging cycling tests, the irreversible change in the electrode thickness was analyzed via dilatometry in the full-cell (Fig. 6a). Liu et al. reviewed the adverse 


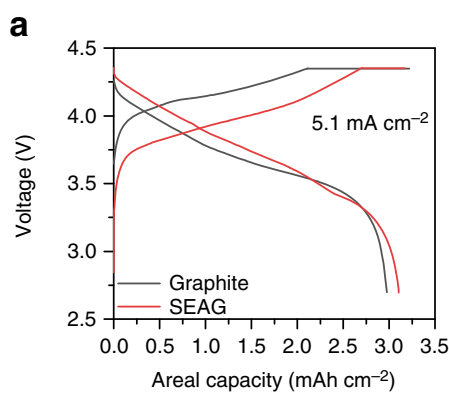

d

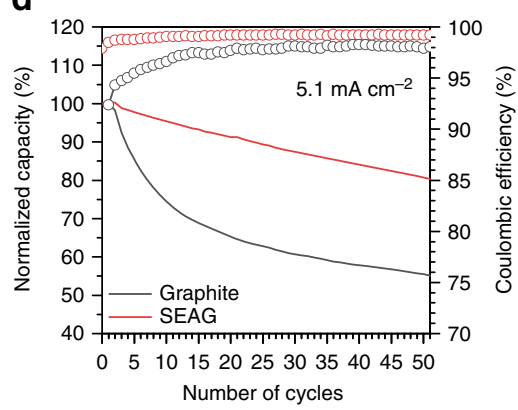

g

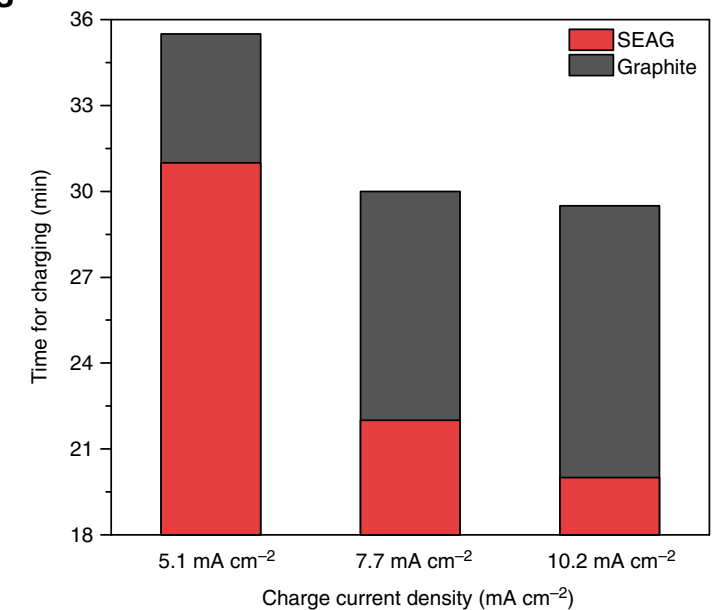

b

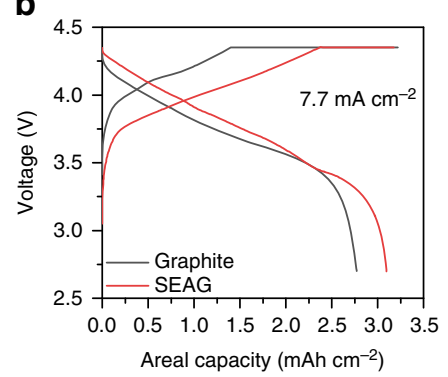

e

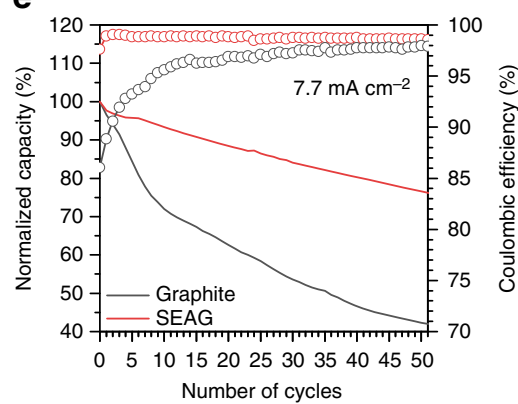

c

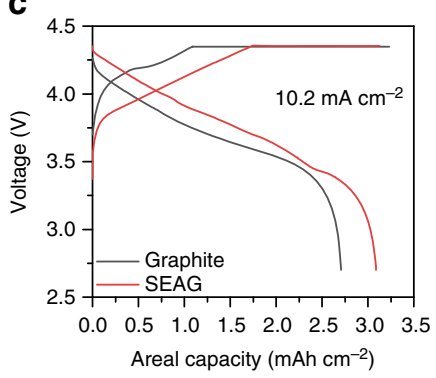

f

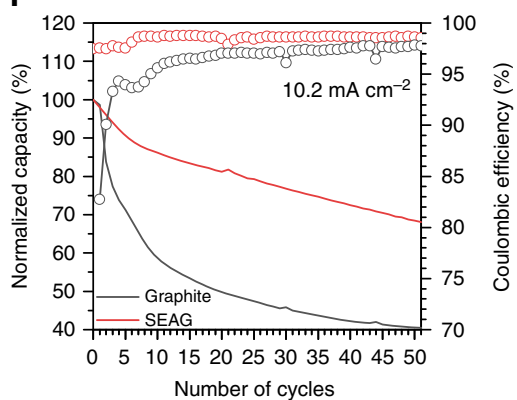

h

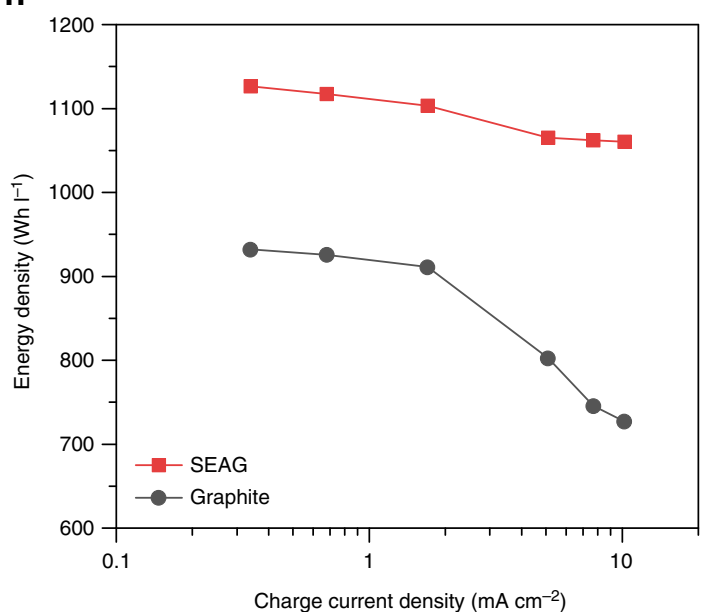

Fig. 5 Fast-charging performance of full-cells with anodes of graphite and the SEAG composite. Voltage profiles at charging current density of a $5.1 \mathrm{~mA} \mathrm{~cm}^{-2}, \mathbf{b} 7.7 \mathrm{~mA} \mathrm{~cm}^{-2}$, and $\mathbf{c} 10.2 \mathrm{~mA} \mathrm{~cm}^{-2}$. Fast-charging cycling performance in the potential range from 4.35 to $2.7 \mathrm{~V}$ for 50 cycles under increasing charging current densities of $\mathbf{d} 5.1 \mathrm{~mA} \mathrm{~cm}^{-2}, \mathbf{e} 7.7 \mathrm{~mA} \mathrm{~cm}^{-2}$, and $\mathbf{f} 10.2 \mathrm{~mA} \mathrm{~cm}$. The discharging current density was fixed at $1.7 \mathrm{~mA} \mathrm{~cm} \mathrm{~cm}^{-2}$ in all cycling tests. $\mathbf{g}$ Time required to charge to $80 \%$ of $\mathrm{SOC}$ at each current density. $\mathbf{h}$ Plot of volumetric energy density vs. applied charging current density for graphite and SEAG. The volumetric energy densities were calculated from the total thickness of both the cathode and anode, considering the electrode volume expansion at the lithiated state during the first cycle. In the electrode composed of SEAG, a volumetric energy density of $1060 \mathrm{Wh} \mathrm{I}^{-1}$ was delivered under an applied charging current density of $10.2 \mathrm{~mA} \mathrm{~cm}^{-2}$

effects of lithium plating, which brought about a drastic energy loss and raised the internal resistance of the cell; these results originated from the irreversible consumption of $\mathrm{Li}^{+}$ions and a thickened solid electrolyte interphase layer that involved the depletion of electrolyte ${ }^{5}$. In addition, the continuous growth of metallic lithium induces an internal short circuit, which is considered a safety issue ${ }^{8}$. Therefore, Li plating is regarded as a critical index for battery degradation and as a guide to understanding the rapid energy fading and unstable efficiency, especially under a high charging current density. In this study, we characterized the lithium plating through irreversible dilation, which was estimated by measuring the difference in cell thickness in the delithiated state at high and standard charging rates $\left(7.7 \text { and } 1.7 \mathrm{~mA} \mathrm{~cm}^{-2} \text {, respectively }\right)^{53}$.
Surprisingly, a much smaller thickness change was measured in SEAG when compared with that in graphite, even though $\mathrm{Si}$, which causes large volume expansion, was incorporated into the SEAG. The rapid and continuous increase in the dilation of graphite, which was the result of metallic lithium deposition, signified the drastic capacity degradation. Photographs and SEM images of the electrode that was subjected to high charging current density $\left(7.7 \mathrm{~mA} \mathrm{~cm}^{-2}\right)$ for 50 cycles are shown in Fig. $6 \mathrm{~b}-\mathrm{g}$. The electrode composed of SEAG showed a relatively clear surface without any trace of lithium deposition (Fig. 6b-d). In contrast, a considerable amount of metallic lithium can be observed on the surface of the graphite electrode; the lithium passivated the electrode to reach a thickness of $30 \mu \mathrm{m}$, leading to severe energy loss and irreversible dilation (Fig. 6e-g). 
a



b

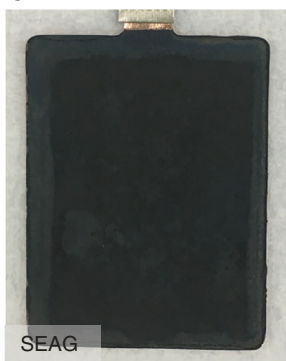

e

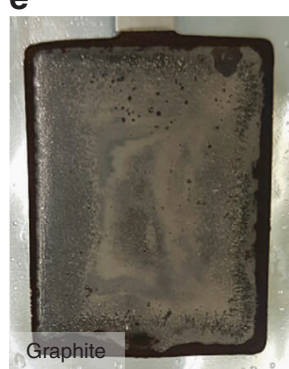

C

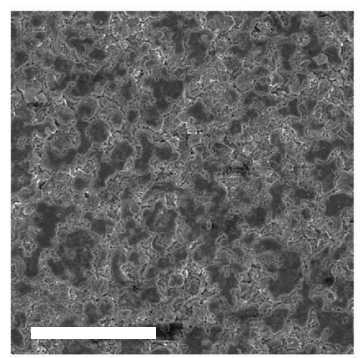

f

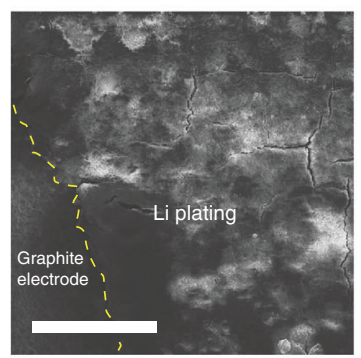

d

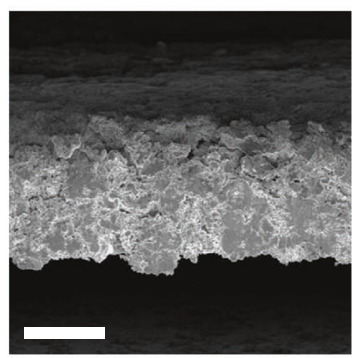

g

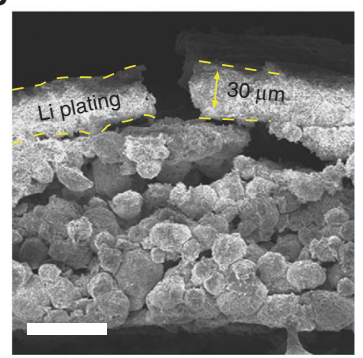

Fig. 6 Dimensional and morphological changes of the electrodes after fast-charging cycles. a Irreversible increase in thickness of the electrode at the delithiated state under $7.7 \mathrm{~mA} \mathrm{~cm}^{-2}$ for 10 cycles. Photographs of $\mathbf{b}$ SEAG electrode and e graphite electrode after $50 \mathrm{cycles}$ at $7.7 \mathrm{~mA} \mathrm{~cm}{ }^{-2}$. Top view and cross-sectional SEM images of $\mathbf{c}, \mathbf{d}$ SEAG electrode and $\mathbf{f}, \mathbf{g}$ graphite electrode. Yellow dash line indicates the deposited Li, which reacted with the electrolyte. Scale bars, c $100 \mu \mathrm{m}, \mathbf{d}, \mathbf{g} 50 \mu \mathrm{m}, \mathbf{f} 400 \mu \mathrm{m}$

In summary, an elaborate SEAG composite, consisting of a-Si nanolayer and edge-plane-activated graphite, was prepared via a simple synthetic route to realize a fast-charging high-energy anode. With this well-developed SEAG, the electrochemical performance of both a half-cell and full-cell were evaluated even under industrial electrode conditions such as high areal capacity loading $\left(\geq 3.4 \mathrm{mAh} \mathrm{cm}^{-2}\right)$ and high electrode density $(\sim 1.6 \mathrm{~g} \mathrm{~cm}$ ${ }^{-3}$ ) with a limited content of conducting agents $(\geq 1 \mathrm{wt} \%)$. In the half-cell, the SEAG achieved a high specific capacity $(525 \mathrm{mAh} g$ ${ }^{-1}$ ) with remarkable $\mathrm{CE}(93.8 \%)$ in the 1 st cycle and good capacity retention $(99.3 \%)$ for 50 cycles. Moreover, at a high charging current density $\left(10.5 \mathrm{~mA} \mathrm{~cm}^{-2}\right)$, the lithiation capacity of SEAG (with relatively stable voltage behavior) was ten times that of the conventional graphite. In the full-cell with high-voltage LCO, the SEAG electrode exhibited enhanced fast charge performance with mitigated polarization and rapidly stabilized $\mathrm{CE}$, leading to a higher volumetric energy density $\left(1060 \mathrm{Wh} \mathrm{l}^{-1}\right)$ with 1.5 times shorter charging time than that of conventional graphite even at a harsh charging current of $10.2 \mathrm{~mA} \mathrm{~cm}^{-2}$. Furthermore, despite the $\mathrm{Si}$ content in SEAG, a much smaller irreversible increase in the electrode thickness $(2 \mu \mathrm{m})$ was observed than in the graphite $(9 \mu \mathrm{m})$, without any trace of lithium plating at a high charging current density $\left(7.7 \mathrm{~mA} \mathrm{~cm}^{-2}\right)$. Concomitantly, we believe that the fast-charging properties can be further improved by increasing the ionic and electric conductivities with electrolyte modifications and advancement in cathode materials. Such excellent electrochemical performance of SEAG clearly demonstrates its viability in fast rechargeable high-energy battery applications.

\section{Methods}

Synthesis of SEAG. For the Ni adsorption on the graphite, $50 \mathrm{~g}$ of pristine graphite (MCMB, Osaka gas), $6 \mathrm{~g}$ of nickel chloride hexahydrate $\left(\mathrm{NiCl}_{2} \cdot 6 \mathrm{H}_{2} \mathrm{O}\right.$, $>97.0 \%$, JUNSEI), and $0.2 \mathrm{~g}$ of sodium hydroxide (anhydrous $\mathrm{NaOH},>98.0 \%$, bead form, SAMCHUN) were dissolved in methanol ( $>99.5 \%$, SAMCHUN)/deionized water $(5: 5, \mathrm{v} / \mathrm{v})$, followed by the addition of $1 \mathrm{ml}$ of hydrazine monohydrate $\left(\mathrm{N}_{2} \mathrm{H}_{4} \cdot \mathrm{H}_{2} \mathrm{O}, 98.0 \%\right.$, Sigma-Aldrich). The solution was heated at $78^{\circ} \mathrm{C}$ for $30 \mathrm{~min}$ in air atmosphere by reflux technique. The $\mathrm{Ni}$ adsorbed graphite was obtained through the centrifugation. In order to trigger the catalytic hydrogenation, the prepared samples were annealing in the furnace at $1000^{\circ} \mathrm{C}$ for $3 \mathrm{~h}$ under $\mathrm{H}_{2}$ $(99.999 \%, \mathrm{KOSEM})$ atmosphere $(1000 \mathrm{sccm})$. In succession, for the formation of both the graphitic carbon shell and a-Si nanolayer on the graphite, $\mathrm{C}_{2} \mathrm{H}_{2}$ gas $\left(10.0 \%, \mathrm{~N}_{2}\right.$ balance, KOSEM) was flowed at $900{ }^{\circ} \mathrm{C}$ for $10 \mathrm{~min}(1000 \mathrm{sccm})$ and then $\mathrm{SiH}_{4}$ gas $\left(99.9999 \%\right.$, KOSEM) was introduced into the furnace at $500^{\circ} \mathrm{C}$ for $30 \mathrm{~min}(50 \mathrm{sccm})$. In case of SEAG with $\mathrm{Ni}$ silicide, the process of $\mathrm{C}_{2} \mathrm{H}_{2}$ flow was omitted.

Materials characterization. Structural characterization of the samples was carried out using SEM (Verios 460, FEI). Dual beam FIB (Helios 450HP, FEI) was performed for scanning the particles in the cross-sectional view. HR-TEM (JEM2100F, FEI) was conducted for detailed analysis. EDS was utilized in SEM (EDS, XFlash 6130, Bruker) and in HR-TEM (EDS, Aztec, Oxford). The oxide layer on aSi surface was analyzed by XPS (K-alpha, Thermo Fisher). XRD (D/Max2000, Rigaku) was carried out for the powder analysis using $\mathrm{Cu}$-Ka radiation, a scan range of $20^{\circ}-80^{\circ}$, a step size of $0.02^{\circ}$, and a counting time of $5 \mathrm{~s}$. Particle size distribution was measured by the Fraunhofer approximation by laser diffraction 
particle size analysis instrument (Microtrac S3500, Microtrac). Tap density was determined by density analyzer (GeoPyc 1360, micromeritics). Specific surface area was estimated with the BET theory with porosity and surface area analyzer (TriStar II, micromeritics)

Electrochemical characterization. For fabrication of the working electrode, the slurry composed of the active material, the conductive agent (Super P, Timcal), and the binder materials (sodium carboxymethyl cellulose (CMC, Nippon paper) and SBR (Zeon)) was uniformly mixed by homogenizer in the mass ratio of 96:1:1.5:1.5 and casted onto the copper foil up to $3.5 \mathrm{mAh} \mathrm{cm} \mathrm{cm}^{-2}$ of areal capacity loading. In sequence, the electrode was dried at $80^{\circ} \mathrm{C}$ and calendared for $1.6 \mathrm{~g} \mathrm{~cm}^{-3}$ of electrode density by roll press. The electrode underwent vacuum drying at $110^{\circ} \mathrm{C}$ for $12 \mathrm{~h}$. In order to assemble the cell, CR2032 (half-cell) and pouch (full-cell) type cell were utilized in argon-filled glove box and dry room, respectively. In case of halfcell, lithium metal ( $>99 \%$, Honjo metal) was used as counter electrode. The electrolyte was $1.3 \mathrm{M} \mathrm{LiPF}_{6}$ in mixture of ethylene carbonate/ethyl methyl carbonate/diethyl carbonate $(3 / 5 / 2$, by volume) with $10 \%$ of fluoroethylene carbonate, $0.2 \%$ of lithium tetrafluoroborate, $0.5 \%$ of vinylene carbonate, $3 \%$ of succinonitrile, and $1 \%$ of propane sultone (Panax Starlyte). As a separator, microporous polyethylene $(15 \mu \mathrm{m}$, Celgard) was used. Electrochemical properties of the half-cell were estimated under the potential window from 0.005 to $1.5 \mathrm{~V}$ for the first cycle, and from 0.005 to $1.0 \mathrm{~V}$ for the rest of cycles. In full-cell, single-crystal lithium cobalt oxide (LCO, homemade) was adopted as cathode electrode with 1:1 of N/P ratio. The cathode electrode was fabricated with active material, carbon black, and polyvinylidene fluoriade binder (PvdF, Solef) in mass ratio of 96:2:2. The mass loading level of the cathode was $20 \mathrm{mg} \mathrm{cm}^{-2}$ and the electrode density was tuned up to $3.6 \mathrm{~g} \mathrm{~cm}^{-3}$. Electrochemical tests of the full-cell were performed in the voltage window between 2.7 and $4.35 \mathrm{~V}$. All electrochemical tests were conducted using a battery cycler (TOSCAT-3100, Toyo system).

Dilatometry. The irreversible volume expansion of the electrode was measured at delithiated state as the thickness difference between in case of high charging rate $\left(7.7 \mathrm{~mA} \mathrm{~cm}^{-2}\right)$ and standard charging rate $\left(1.7 \mathrm{~mA} \mathrm{~cm}^{-2}\right)$. The discharging current density was fixed as $1.7 \mathrm{~mA} \mathrm{~cm}^{-2}$ in both cases. Thickness change was estimated by dilatometer (Mitutoyo)

Data availability. The authors declare that the data supporting the findings of this study are available within the article and its Supplementary Information files. All other relevant data supporting the findings of this study are available on request.

Received: 20 January 2017 Accepted: 10 August 2017

Published online: 09 October 2017

\section{References}

1. Takami, N., Satoh, A., Hara, M. \& Ohsaki, T. Structural and kinetic characterization of lithium intercalation into carbon anodes for secondary lithium batteries. J. Electrochem. Soc. 142, 371-379 (1995).

2. Levi, M. D. \& Aurbach, D. Diffusion coefficients of lithium ions during intercalation into graphite derived from the simultaneous measurements and modeling of electrochemical impedance and potentiostatic intermittent titration characteristics of thin graphite electrodes. J. Phys. Chem. B 101, 4641-4647 (1997)

3. Yu, P., Popov, B. N., Ritter, J. A. \& White, R. E. Determination of the lithium ion diffusion coefficient in graphite. J. Electrochem. Soc. 146, 8-14 (1999).

4. Nitta, N. \& Yushin, G. High-capacity anode materials for lithium-ion batteries: choice of elements and structures for active particles. Part. Part. Syst. Char. 31, 317-336 (2014).

5. Liu, Q. et al. Understanding undesirable anode lithium plating issues in lithium-ion batteries. RSC Adv. 6, 88683-88700 (2016).

6. Waldmann, T., Wilka, M., Kasper, M., Fleischhammer, M. \& WohlfahrtMehrens, M. Temperature dependent ageing mechanisms in Lithium-ion batteries-a post-mortem study. J. Power Sources 262, 129-135 (2014).

7. Smart, M. C. \& Ratnakumar, B. V. Effects of electrolyte composition on lithium plating in lithium-ion cells. J. Electrochem. Soc. 158, A379-A389 (2011).

8. Aurbach, D., Zinigrad, E., Cohen, Y. \& Teller, H. A short review of failure mechanisms of lithium metal and lithiated graphite anodes in liquid electrolyte solutions. Solid State Ionics 148, 405-416 (2002).

9. Ouyang, $\mathrm{M}$. et al. Overcharge-induced capacity fading analysis for large format lithium-ion batteries with $\mathrm{Li}_{y} \mathrm{Ni}_{1 / 3} \mathrm{Co}_{1 / 3} \mathrm{Mn}_{1 / 3} \mathrm{O}_{2}+\mathrm{Li}_{y} \mathrm{Mn}_{2} \mathrm{O}_{4}$ composite cathode. J. Power Sources 279, 626-635 (2015).

10. Yang, L. et al. Lithium deposition on graphite anode during long-term cycles and the effect on capacity loss. RSC Adv. 4, 26335-26341 (2014).

11. Gallagher, K. G. et al. Optimizing areal capacities through understanding the limitations of lithium-ion electrodes. J. Electrochem. Soc. 163, A138-A149 (2016).
12. Cheng, Q., Yuge, R., Nakahara, K., Tamura, N. \& Miyamoto, S. KOH etched graphite for fast chargeable lithium-ion batteries. J. Power Sources 284, 258-263 (2015).

13. Obrovac, M. N. \& Chevrier, V. L. Alloy negative electrodes for Li-ion batteries Chem. Rev. 114, 11444-11502 (2014).

14. Ko, M., Chae, S. \& Cho, J. Challenges in accommodating volume change of Si anodes for Li-ion batteries. ChemElectroChem 2, 1645-1651 (2015).

15. $\mathrm{Su}, \mathrm{X}$. et al. Silicon-based nanomaterials for lithium-ion batteries: a review. $A d v$ Energy Mater. 4, 1300882 (2014).

16. Park, C.-M., Kim, J.-H., Kim, H. \& Sohn, H.-J. Li-alloy based anode materials for Li secondary batteries. Chem. Soc. Rev. 39, 3115-3141 (2010).

17. Zhang, W.-J. A review of the electrochemical performance of alloy anodes for lithium-ion batteries. J. Power Sources 196, 13-24 (2011)

18. Deng, T. \& Zhou, X. Porous graphite prepared by molybdenum oxide catalyzed gasification as anode material for lithium ion batteries. Mater. Lett. 176, 151-154 (2016).

19. Liang, J. et al. A deep reduction and partial oxidation strategy for fabrication of mesoporous Si anode for lithium ion batteries. ACS Nano 10, 2295-2304 (2016).

20. Lin, L., Xu, X., Chu, C., Majeed, M. K. \& Yang, J. Mesoporous amorphous silicon: a simple synthesis of a high-rate and long-life anode material for lithium-ion batteries. Angew. Chem. Int. Ed. 55, 14063-14066 (2016).

21. Yuge, R., Tamura, N., Manako, T., Nakano, K. \& Nakahara, K. High-rate charge/discharge properties of Li-ion battery using carbon-coated composites of graphites, vapor grown carbon fibers, and carbon nanohorns. J. Power Sources 266, 471-474 (2014).

22. Gohier, A. et al. High-rate capability silicon decorated vertically aligned carbon nanotubes for Li-ion batteries. Adv. Mater. 24, 2592-2597 (2012).

23. Yi, R., Zai, J., Dai, F., Gordin, M. L. \& Wang, D. Dual conductive networkenabled graphene/Si-C composite anode with high areal capacity for lithiumion batteries. Nano Energy 6, 211-218 (2014).

24. Chae, S. et al. Micron-sized Fe-Cu-Si ternary composite anodes for high energy Li-ion batteries. Energy Environ. Sci. 9, 1251-1257 (2016).

25. Cao, F.-F. et al. Cu-Si nanocable arrays as high-rate anode materials for lithium-ion batteries. Adv. Mater. 23, 4415-4420 (2011).

26. Buqa, H., Goers, D., Holzapfel, M., Spahr, M. E. \& Novák, P. High rate capability of graphite negative electrodes for lithium-ion batteries. J. Electrochem. Soc. 152, A474-A481 (2005).

27. Keep, C. W., Terry, S. \& Wells, M. Studies of the nickel-catalyzed hydrogenation of graphite. J. Catal. 66, 451-462 (1980).

28. Goethel, P. J. \& Yang, R. T. Mechanism of graphite hydrogenation catalyzed by nickel. J. Catal. 108, 356-363 (1987).

29. Jeong, S. et al. Etched graphite with internally grown Si nanowires from pores as an anode for high density Li-ion batteries. Nano Lett. 13, 3403-3407 (2013).

30. Lukas, M. et al. Catalytic subsurface etching of nanoscale channels in graphite. Nat. Commun. 4, 1379 (2013).

31. Qiu, Z., Song, L., Zhao, J., Li, Z. \& Yang, J. The nanoparticle size effect in graphene cutting: a "Pac-Man" mechanism. Angew. Chem. Int. Ed. 55, 9918-9921 (2016).

32. Mukhopadhyay, A. et al. Engineering of graphene layer orientation to attain high rate capability and anisotropic properties in Li-ion battery electrodes. $A d v$. Funct. Mater. 23, 2397-2404 (2013).

33. Zaghib, K., Nadeau, G. \& Kinoshita, K. Influence of edge and basal plane sites on the electrochemical behavior of flake-like natural graphite for Li-ion batteries. J. Power Sources 97-98, 97-103 (2001).

34. Persson, K. et al. Lithium diffusion in graphitic carbon. J. Phys. Chem. Lett. 1 , 1176-1180 (2010).

35. Zhang, J. et al. Rational synthesis of Ni nanoparticle-embedded porous graphitic carbon nanosheets with enhanced lithium storage properties. Nanoscale 7, 18211-18217 (2015).

36. Du, Z., Dunlap, R. A. \& Obrovac, M. N. High energy density calendered Si alloy/graphite anodes. J. Electrochem. Soc. 161, A1698-A1705 (2014).

37. Lin, D. et al. A high tap density secondary silicon particle anode fabricated by scalable mechanical pressing for lithium-ion batteries. Energy Environ. Sci. 8, 2371-2376 (2015).

38. Ko, M. et al. Scalable synthesis of silicon-nanolayer-embedded graphite for high-energy lithium-ion batteries. Nat. Energy 1, 16113 (2016).

39. Wu, H. \& Cui, Y. Designing nanostructured Si anodes for high energy lithium ion batteries. Nano Today 7, 414-429 (2012).

40. Kim, H. et al. Nanocomb architecture design using germanium selenide as high-performance lithium storage material. Chem. Mater. 28, 6146-6151 (2016).

41. Ogata, K., Sutter, E., Zhu, X. \& Hofmann, S. Ni-silicide growth kinetics in Si and $\mathrm{Si} / \mathrm{SiO}_{2}$ core/shell nanowires. Nanotechnology 22, 469601 (2011).

42. Leonard, F. \& Talin, A. A. Electrical contacts to one- and two-dimensional nanomaterials. Nat. Nano 6, 773-783 (2011).

43. Chen, Y. et al. Kinetic manipulation of silicide phase formation in Si nanowire templates. Nano Lett. 13, 3703-3708 (2013). 
44. Hensel, J. C., Tung, R. T., Poate, J. M. \& Unterwald, F. C. Electrical transport properties of $\mathrm{CoSi}_{2}$ and $\mathrm{NiSi}_{2}$ thin films. Appl. Phys. Lett. 44, 913-915 (1984).

45. Du, Z., Hatchard, T. D., Bissonnette, P., Dunlap, R. A. \& Obrovac, M. N. Electrochemical activity of nano- $\mathrm{NiSi}_{2}$ in Li cells. J. Electrochem. Soc. 163 , A2456-A2460 (2016).

46. Chae, S. J. et al. Synthesis of large-area graphene layers on poly-nickel substrate by chemical vapor deposition: wrinkle formation. Adv. Mater. 21, 2328-2333 (2009).

47. Ko, M., Chae, S., Jeong, S., Oh, P. \& Cho, J. Elastic a-silicon nanoparticle backboned graphene hybrid as a self-compacting anode for high-rate lithium ion batteries. ACS Nano 8, 8591-8599 (2014).

48. Huang, B., Zheng, X., Fan, X., Song, G. \& Lu, M. Enhanced rate performance of nano-micro structured $\mathrm{LiFePO} 4 / \mathrm{C}$ by improved process for high-power $\mathrm{Li}$-ion batteries. Electrochim. Acta 56, 4865-4868 (2011).

49. Kasavajjula, U., Wang, C. \& Appleby, A. J. Nano- and bulk-silicon-based insertion anodes for lithium-ion secondary cells. J. Power Sources 163, 1003-1039 (2007).

50. McDowell, M. T. et al. In situ TEM of two-phase lithiation of amorphous silicon nanospheres. Nano Lett. 13, 758-764 (2013).

51. Wang, D.-W., Li, F., Liu, M., Lu, G. Q. \& Cheng, H.-M. 3D aperiodic hierarchical porous graphitic carbon material for high-rate electrochemical capacitive energy storage. Angew. Chem. Int. Ed. 120, 379-382 (2008).

52. Liu, N. et al. A pomegranate-inspired nanoscale design for large-volumechange lithium battery anodes. Nat. Nano 9, 187-192 (2014).

53. Bitzer, B. \& Gruhle, A. A new method for detecting lithium plating by measuring the cell thickness. J. Power Sources 262, 297-302 (2014).

\section{Acknowledgements}

This work was supported by the project from Samsung Research Funding \& Incubation Center of Samsung Electronics Co. Ltd (A Rapid Charging Battery and its Prototype Cells Retaining High Energy Density, SRFC-TA1603-01).

\section{Author contributions}

N.K. and M.K. conceived and designed the experiments. N.K. prepared the samples and carried out all the main experiments. S.C. assisted with the data analysis and conducted dilatometry; J.M. assisted with sample preparation. N.K. and J.C. co-wrote the paper. N.K., S.C., M.K., and J.C. discussed the results and revised or commented the manuscript.

\section{Additional information}

Supplementary Information accompanies this paper at doi:10.1038/s41467-017-00973-y.

Competing interests: The authors declare no competing financial interests.

Reprints and permission information is available online at http://npg.nature.com/ reprintsandpermissions/

Publisher's note: Springer Nature remains neutral with regard to jurisdictional claims in published maps and institutional affiliations.

\section{(c) (1)}

Open Access This article is licensed under a Creative Commons Attribution 4.0 International License, which permits use, sharing, adaptation, distribution and reproduction in any medium or format, as long as you give appropriate credit to the original author(s) and the source, provide a link to the Creative Commons license, and indicate if changes were made. The images or other third party material in this article are included in the article's Creative Commons license, unless indicated otherwise in a credit line to the material. If material is not included in the article's Creative Commons license and your intended use is not permitted by statutory regulation or exceeds the permitted use, you will need to obtain permission directly from the copyright holder. To view a copy of this license, visit http://creativecommons.org/ licenses/by/4.0/

(C) The Author(s) 2017 